\title{
Type II Solar Radio Burst with a Split and Herring - Bones During a Minimum Solar Activity
}

\author{
Z. S. Hamidi ${ }^{1, *}$, N. N. M. Shariff ${ }^{2}$, C. Monstein ${ }^{3}$ \\ ${ }^{1}$ School of Physics and Material Sciences, Faculty of Sciences, MARA University of Technology, \\ 40450, Shah Alam, Selangor, Malaysia \\ ${ }^{2}$ Academy of Contemporary Islamic Studies (ACIS), MARA University of Technology, \\ 40450, Shah Alam, Selangor, Malaysia \\ ${ }^{3}$ Institute of Astronomy, Wolfgang-Pauli-Strasse 27, Building HIT, Floor J, \\ $\mathrm{CH}-8093$ Zurich, Switzerland \\ *E-mail address: zetysh@salam.uitm.edu.my
}

\begin{abstract}
A preliminary correlation study of the herring - bone type II with a type III solar burst of has been made. On the basis of this study and in combination with the observation in radio emission, an interpretation of the mechanism of the occurrence of this event has been proposed. The type II solar radio burst with a split and herring bone is occurring at the same time from $36 \mathrm{MHz}$ till $50 \mathrm{MHz}$. We have noted that an individual type III burst also can be observed at 13:23 UT from 45-50 MHz. During that day, a stream of solar wind from a coronal hole on the Sun has disturbing Earth's magnetosphere creating a minor geomagnetic storm, G1 on the NOAA scale of G1-G5. In this case, the solar flare is not very high, but CME is responsible to form a solar radio burst type II. Overall, based on seven days observation beginning from 25th March 2013, the solar activity is considered as very low. The highest solar flare can be observed within 7 days is only a class of B8 flare. There was no CMEs event that directed to the Earth is detected. The geomagnetic field activities are also at minimum level. Although the solar flare event is at a lower stage, it is still possible to form the solar radio burst type II which is associated with CME event. From the selected event, although theoretically solar radio burst type II is associated with CMEs, there is no compelling solar radio burst type II without a flare. The only difference is the dynamic structure and the intensity and speed of both phenomena (solar flares and CMEs) which depend on the active region. Nevertheless, understanding how energy is released in solar flares is one of the central questions in astrophysics. This solar radio burst type II formation is the first event that successfully detected by e-CALLISTO network in 2013.
\end{abstract}

Keywords: Sun; low frequency; solar radio; burst, type II; e-CALLISTO

\section{INTRODUCTION}

It is widely accepted that the solar radio burst type III plays a fundamental role in solar burst studies [1]. The determination of other solar radio burst types such as type II, IV, V, U, and sub-types are mostly related to the formation of type III [2]. The only difference is either type III form before or after the other burst. Although all the bursts have these features in common, it is seen that they differ widely amongst themselves and that some exhibit other outstanding characteristics. It can associated with type U [3], type IV [4], type V [5] and type II burst [6]. 
The formation of the type II solar burst is based on acceleration of electrons at an outward propagating coronal shock front [7]. One main aspect of this type is that it is the earliest indicators of Coronal Mass Ejections-driven shocks. The onset time of this type precludes the possibility of the CME driven shock [8]. Solar radio burst type II were first identified by [9] and also discovered by [10] and classified as a broadband, lasting from 20 minutes to a few hours. There are five sub-types of solar burst type II, (i) Narrow Bandwidth, (ii) Harmonic Structure, (iii) Band Splitting, (iv) Multiple Bands, (v) Compound Type IIIType II Burst, (iv) Herring-bone Structure and (vii) Other Fine Structure [11]. This burst is based on the evolution of sunspot number and sunspot area [12].

The herring-bones solar burst type II has a unique structure. This burst is one of the main sub-type of solar radio burst type II. It occurred at very low frequency, normally less than $100 \mathrm{MHz}$ [13]. In fact, the bursts represent radiation from oscillations induced in the coronal plasma by the outward passage of a disturbance. Meanwhile, type III solar burst was first introduced by Wild in 1963 [14] in the frequency range 500-10 MHz. This fast drift burst is the most common of the meter wavelength bursts. It is normally found at the pre-flare stage that could be a signature of electron acceleration [15]. It is well known that an isolated type III solar burst can exhibit a wide range of forms [16]. However, [17] against the theory and strongly agree that type III [18] burst requires a very strong field to produce a fundamental and second harmonic of gyro frequency. The subject of nonlinear wave-wave interaction which involving interaction of electrostatic electron plasma that called as Langmuir waves active region radio emissions also have been studied [19-23].

\section{EXPERIMENTAL SETUP AND OBSERVATION}

The CALLISTO system is a dedicated to solar burst observation in the low frequency radio region. In principle, we used a Log Periodic Dipole Antenna (LPDA) which is mounted on the top of the rooftop of National Space Centre (ANGKASA) building at Sg. Lang, Banting, Selangor located at $\left(\mathrm{N} 02^{\circ} 49.488^{\prime} \mathrm{E} 101^{\circ} 36.168^{\prime}\right)$ that covered the range of frequency from $85-470 \mathrm{MHz}$ [24].. This 5.5 meters antenna is connected to the CALLISTO spectrometer via cable RG 58 and the modification, calibration process and basic analysis of the antenna has been done in order to improve the feature of the system [25-29]. In order to improve the ratio of the gain, a preamplifier also is used. These data are automatically saved in FIT files. On the other hand, due to constrain of the interference factors, the range of 150 $\mathrm{MHz}$ till $350 \mathrm{MHz}$ had been chosen as selected data [30-46]. We have start a daily routine of 12 hour solar observations per day since $20^{\text {th }}$ of February 2012 [32]. Several sites are also using the radio telescope with the antenna as a detector and this will improve the resolution of the burst. During this event, there are several sites such as (a) BIR Ireland, (b) Glasgow and (c) Humain were successfully detected this burst between 13:20-13:30 UT on 30th March 2013 such as KASI Korea and SSRT Switzerland. Based on the data, the burst is formed within four minutes. There is also a long fast-drift type type III solar burst was recorded before the formation type II solar burst. This type III solar burst is ejecting intermittently before and after the formation of type II solar burst.

\section{RESULTS AND ANALYSIS}

The latest event solar radio burst type II associated with the Coronal Mass Ejections (CMEs) event during 30th March 2013 is highlighted. It implies that the outward-travelling 
disturbance responsible for the type II band is a source which ejects rapidly travelling disturbances. There was a CMEs event between 13:22 and 13:33 UT due to region AR 1708. This event is successfully detected from a few e-CALLISTO networks such as Glasgow, Royal Observatory of Belgium and BIR observatory, Ireland. The burst began as a fairly typical harmonic type II, but after the burst had been in progress for approximately 3 minutes, rapidly drifting elements suddenly appeared extending from the low frequency side of each of the harmonic bands.

The observations reported in this paper were made with a type II solar radio burst with a split and herring bones is occurring at 13:23 UT from $36 \mathrm{MHz}$ till $50 \mathrm{MHz}$. At the lower frequencies the weak signals that can be clearly detected. We have noted that an individual type III burst also can be observed at the same time, 13:23 UT from 45-50 MHz. The fast drift burst is occurring within a minute before type II burst form. This region is very low and less that the limitation of our log periodic dipole antenna specification. During that day, a stream of solar wind from a coronal hole on the Sun has disturbing Earth's magnetosphere creating a minor geomagnetic storm, G1 on the NOAA scale of G1-G5. Detail X-ray flux within seven days and solar radio burst type II is presented in Figure 1 and Figure 2.

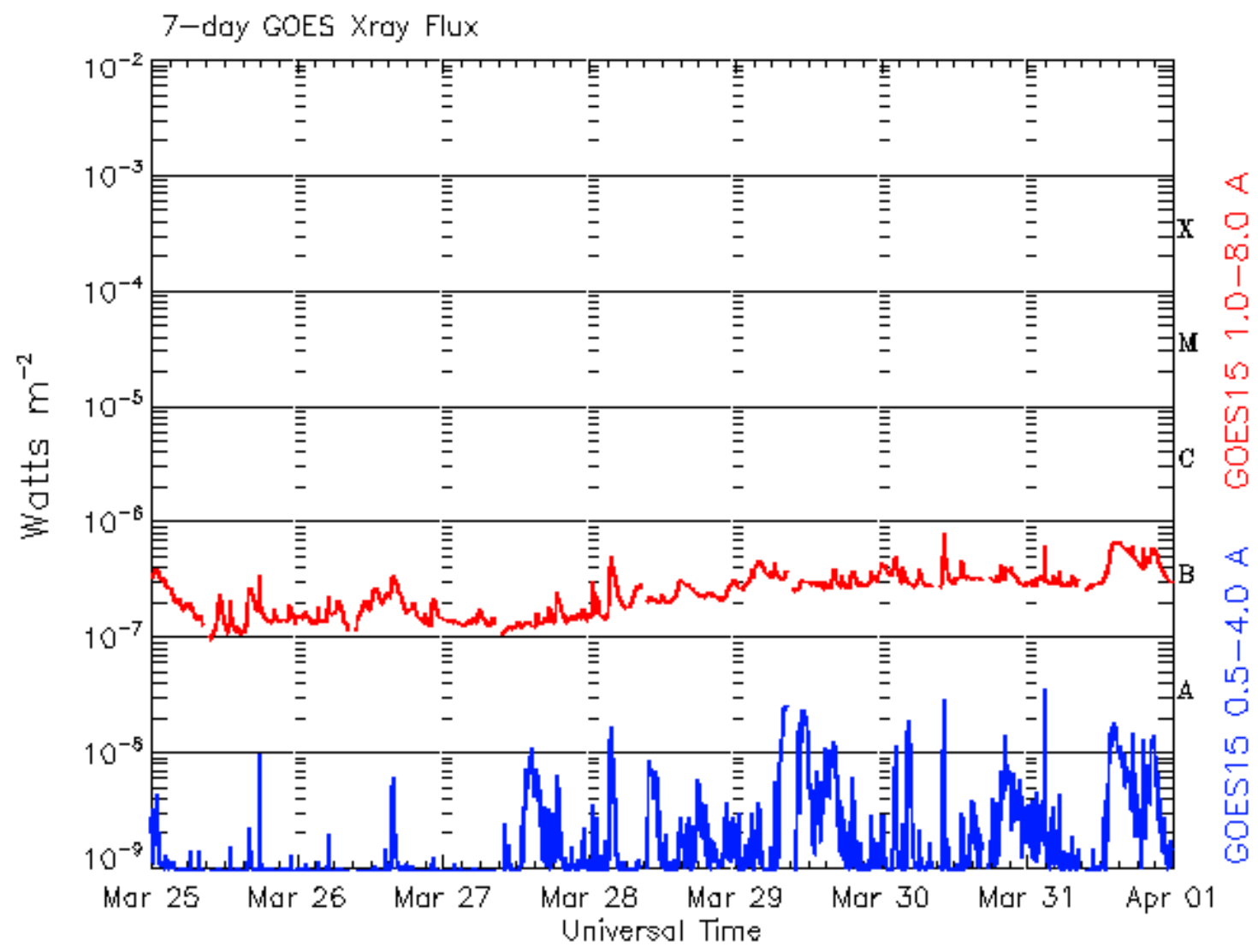

Figure 1. GOES X-ray flux from $25^{\text {th }}$ of March 2013 till $1^{\text {st }}$ of April 2013. 

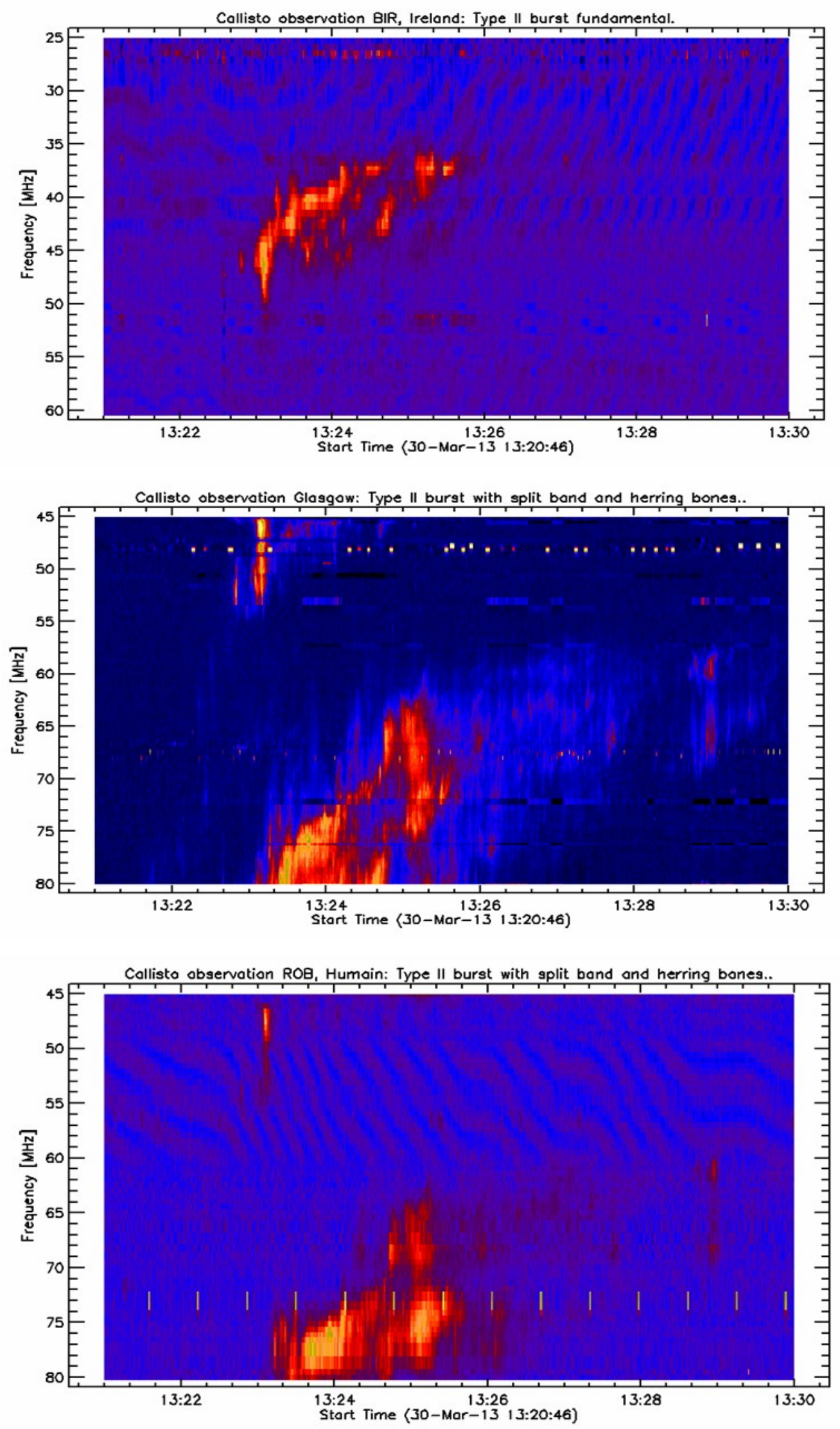

Figure 2. Solar radio burst type II at different sites (a) BIR Ireland, (b) Glasgow and (c) Humain. 
Next, we consider the other parameters that related to the event. Before the formation of solar radio burst type II, it has been observed a continuous solar radio burst type III since 10:36 UT which means that it take about 3 hours to form SRBT II. However, the group of type III is intermittent and sometimes it form as an individual type III. Other solar parameters that contribute the event are presented in Table 1

Table 1. Solar parameters on $30^{\text {th }}$ March 2013.

\begin{tabular}{|c|c|}
\hline Parameter & Value \\
\hline Solar wind & $529.5 \mathrm{~km} / \mathrm{sec}$ \\
\hline Density & 1.9 protons $/ \mathrm{cm}^{3}$ \\
\hline X-ray Solar Flares : B4 :1944 UT & 6-hr max \\
\hline : B8 1024 UT & 24-hr \\
\hline Sunspot number & 73 \\
\hline
\end{tabular}

It is obvious from these diagrams that the flares and type II bursts are associated. In this case, the solar flare is not very high, but the CME is responsible to form a solar radio burst type II. This means that the CMEs event still can be exploded, although the class of solar flare is B -class. This event is interesting to be tackled. It is very rare for a type II burst to be form during low activity of the Sun. In this case, the active region plays an important role. The magnetic reconnection at the particular active region has a potential to accelerate the particles outside the atmosphere of the Sun. From the space observation, the sunspots number also in a minimum value with 73 . Overall, based on seven days observation beginning from 25 th March 2013, the solar activity is considered as very low. The highest solar flare can be observed within 7 days is only a B8 type flare. There was no CMEs event that directed to the Earth is detected. The geomagnetic field activities are also at minimum level. However, there is a tendency that the active region will continue active in the next few days.

\section{CONCLUSIONS}

In concluding this event, although the solar flare event is at a lower stage, it is still possible to form the solar radio burst type II which is associated with CME event. This solar radio burst type II formation is the first event that successfully detected by e-CALLISTO network in 2013 and it is hoped that there will more solar radio burst type II associated with CMEs and solar flares can be observed. From the selected events, although theoretically solar radio burst type II is associated with CMEs, there is no compelling solar radio burst type II without a flare. The only difference is the dynamic structure and the intensity and speed of both phenomena (solar flares and CMEs) which depend on the active region. Nevertheless, understanding how energy is released in solar flares is one of the central questions in astrophysics. The morphology of thermal and non-thermal flare plasma is of particular significance because it holds many important signatures of the energy release process. To this point of discussion, the onsets of solar flares and Coronal Mass Ejections (CMEs) have been studied as well. 


\section{ACKNOWLEDGEMENT}

We are grateful to LASCO,SDO/AIA, NOAA and SWPC make their data available online. This work was partially supported by the PPP UM PV071/2011B grants. Special thanks to C. Monstein from ETH Zurich, Switzerland who set up and gives us training on analyzing the data. Also to National Space Agency and National Space Centre for giving us a site to set up this project and support this project. Solar burst monitoring is a project of cooperation between the Institute of Astronomy, ETH Zurich, and FHNW Windisch, Switzerland, MARA University of Technology and University of Malaya. This paper also used NOAA Space Weather Prediction Centre (SWPC) for the sunspot, radio flux and solar flare data for comparison purpose. The research has made use of the National Space Centre Facility and a part of an initiative of the International Space Weather Initiative (ISWI) program.

\section{BIOGRAPHY}

Dr Zety Sharizat Hamidi is currently a lecturer and focused in Solar Astrophysics research specifically in radio astrophysics at the School of Physics and Material Sciences, Faculty of Sciences, MARA University of Technology, 40450, Shah Alam, Selangor, Malaysia. Involve a project under the International Space Weather Initiative (ISWI).

C. Monstein is a senior Engineer at Institute of Astronomy, Wolfgang-Pauli-Strasse 27, Building HIT, Floor J, CH-8093 Zurich, Switzerland and one of the researchers who initiated the CALLISTO system around the world.

Dr Nur Nafhatun Md Shariff is a senior lecturer in Academy of Contemporary Islamic Studies (ACIS), MARA University of Technology, 40450, Shah Alam, Selangor, Malaysia.Her current research is more on sustainability; environmental aspect. She is looking forward for cross-field research, i.e. solar astrophysics, light pollution measurement (mapping) and religious studies.

\section{References}

[1] M.R. Kundu, Solar Radio Astronomy, John Wiley, 1965.

[2] Z. Hamidi, Z. Abidin, Z. Ibrahim, C. Monstein, N. Shariff, M. Sabaghi, International Journal of Fundamental Physical Sciences 2(2) (2012) 29-31.

[3] Z. Hamidi, N. Shariff, C. Monstein, International Letters of Chemistry, Physics and Astronomy 10 (2014) 81-90.

[4] Z. Hamidi, Z. Abidin, Z. Ibrahim, C. Monstein, N. Shariff, International Journal of Fundamental Physical Sciences 2(2) (2012) 21-23.

[5] Z. Hamidi, Z. Abidin, Z. Ibrahim, C. Monstein, N. Shariff, International Journal Physical Fundamental Sciences 2(3) (2012) 32-34.

[6] Z. Hamidia, Z. Abidina, Z. Ibrahima, N. Shariffa, C. Monsteinc, Observations of Coronal Mass Ejections (CMEs) at Low Frequency Radio Region on 15th April 2012, AIP Conf. Proc 1528 (2013) 55-60.

[7] N. Gopalswamy, P. Makela, H. Xie, S. A. Y. Akiyama, S. Yashiro, Journal Geophysical Research: Speace Physics 114(A3) (2009) A00-A22.

[8] N. Gopalswamy, N. Nitta, P.K. Manoharan, A. Raoult, M. Pick, Astronomy and Astrophysics 347 (1999) 684-695.

[9] R. Payne-Scott, D.E. Yabsley, J.G. Bolton, Nature 160 (1947) 256-257.

[10] Boischot A., C. R. Acad. Sci. 244 (1957) 1326. 
[11] Z. Hamidi, U.F.S.U. Ibrahim, Z. Abidin, Z. Ibrahim, N. Shariff, International Journal Physical Fundamental Sciences 3 (2013) 20-23.

[12] Z. Hamidi, N. Shariff, F.Z. Ulum, Z. Abidin, Z. Ibrahim, International Journal of Astronomy 1 (2012) 101-104.

[13] Z. Hamidi, N. Shariff, C. Monstein, International Letters of Chemistry, Physics and Astronomy 12 (2014) 84-102.

[14] J. P. Wild, Smerd S. F., Weiss A. A., Solar Burst, Ann. Rev. Astron. Astrophysics 1 (1963) 291-366.

[15] G.A. Dulk, Type III solar radio bursts at long wavelengths, in: R. Stone, E. Weiler, M. Goldstein (Eds.), Geophys. Monogr., 2000.

[16] T. Takakura, Pub. Astron. Soc. Japan 12 (1960).

[17] A.F. Kuckes, Sudan R.N, Sol. Phys. 17 (1971).

[18] K. Kai, Sol. Phys. 11 (1970).

[19] G. B. L. Gelfreikh, Soviet Astron. 23 (1979).

[20] P. Lantos, Sol. Phys. 22 (1972).

[21] A. Vourlidas, Bastian T. S., Nitta N., Aschwanden M. J., Sol. Phys. 163 (1996).

[22] E. Y. Zlotnik, Soviet Astron. 12 (1968).

[23] V. V. Zheleznyakov, Radio Emission of the Sun and Planets (1970).

[24] Z.S. Hamidi, Z. Ibrahim, Z. Abidin, M. Maulud, N. Radzin, N. Hamzan, N. Anim, N. Shariff, International Journal of Applied Physics and Mathematics 2 (2011) 3.

[25] Z.S.Hamidi, S. Chumiran, A. Mohamad, N. Shariff, Z. Ibrahim, N. Radzin, N. Hamzan, N. Anim, A. Alias, American Journal of Modern Physics 2 (2013) 4.

[26] Z.S.Hamidi, Z. Abidin, Z. Ibrahim, N. Shariff, C. Monstein, International Journal of Engineering Research and Development 3 (2012) 36-39.

[27] Z.S.Hamidi, Z. Abidin, Z. Ibrahim, C. Monstein, N. Shariff, International Journal of Fundamental Physical Sciences 2 (2012) 32-34.

[28] Z.S.Hamidi, N.M.Anim, N. N.S.Hakimi, N.Hamzan, A.Mokhtar, N.Syukri, S.Rohizat, I.Sukma, Z.A. Ibrahim, Z.Z.Abidin, N.N.M.Shariff, C.Monstein, International Journal of Fundamental Physical Sciences 2 (2012) 4.

[29] Z.S.Hamidi, N.N.M. Shariff, International Journal of Science and Mathematics 2 (2014) 3.

[30] Z.S.Hamidi, Z. Abidin, Z. Ibrahim, N. Shariff, Indication of radio frequency interference (RFI) sources for solar burst monitoring in Malaysia, ICPAP 2011, AIP Publisher, Indonesia, 2012, pp. 6.

[31] Z.S. Hamidi, N.N.M. Shariff, C. Monstein, The International Journal of Engineering 1 (2012) 3 .

[32] Z.S. Hamidi, N. Shariff, Z. Abidin, Z. Ibrahim, C. Monstein, Middle-East Journal of Scientific Research 12 (2012) 6. 
[33] Z. S. Hamidi, N. N. M. Shariff, C. Monstein, International Letters of Chemistry, Physics and Astronomy 13(1) (2014) 77-87.

[34] Z. S. Hamidi, N. N. M. Shariff, International Letters of Chemistry, Physics and Astronomy 4 (2014) 29-36.

[35] Z. S. Hamidi, N. N. M. Shariff, International Letters of Chemistry, Physics and Astronomy 5 (2014) 32-42.

[36] Z. S. Hamidi, N. N. M. Shariff, International Letters of Chemistry, Physics and Astronomy 5 (2014) 43-49.

[37] Z. S. Hamidi, N. N. M. Shariff, International Letters of Chemistry, Physics and Astronomy 7 (2014) 21-29.

[38] Z. S. Hamidi, N. N. M. Shariff, International Letters of Chemistry, Physics and Astronomy 7 (2014) 30-36.

[39] Z. S. Hamidi, N. N. M. Shariff, C. Monstein, Z. A. Ibrahim, International Letters of Chemistry, Physics and Astronomy 7 (2014) 37-44.

[40] Z. S. Hamidi, N. N. M. Shariff, C. Monstein, W. N. A. Wan Zulkifli, M. B. Ibrahim, N. S. Arifin, N. A. Amran, International Letters of Chemistry, Physics and Astronomy 8 (2014) 13-19.

[41] Z. S. Hamidi, N. N. M. Shariff, C. Monstein, W. N. A. Wan Zulkifli, M. B. Ibrahim, N. S. Arifin, N. A. Amran, International Letters of Chemistry, Physics and Astronomy 9 (2014) 8-15.

[42] Z. S. Hamidi, N. N. M. Shariff, M. F. Ali, C. Monstein, W. N. A. Wan Zulkifli, M. B. Ibrahim, N. S. Arifin, N. A. Amran, International Letters of Chemistry, Physics and Astronomy 9 (2014) 84-92.

[43] Z. S. Hamidi, N. N. M. Shariff, C. Monstein, International Letters of Chemistry, Physics and Astronomy 11(1) (2014) 51-58.

[44] Z. S. Hamidi, N. N. M. Shariff, C. Monstein, International Letters of Chemistry, Physics and Astronomy 11(2) (2014) 135-145.

[45] Z. S. Hamidi, N. N. M. Shariff, C. Monstein, International Letters of Chemistry, Physics and Astronomy 11(2) (2014) 167-176.

[46] Z. S. Hamidi, C. Monstein, N. N. M. Shariff, International Letters of Chemistry, Physics and Astronomy 11(3) (2014) 243-256. 